\title{
Reviews of Books
}

Susgestion and Common Sense. R. Allan Bennett, M.D. Lond, M.R.C.P. Pp. 105. Bristol: John Wright \& Sons, Ltd. Price 6s. net.

Twenty years ago, on the advice of the late Dr Mercier, Dr Bennett decided to "shun psychology and cling to that which is good." Notwithstanding this attitude of independence, the first two chapters of the book are devoted to "Psychology and Organic Life" and "Psychology and Disease" respectively. The remainder of the book deals with suggestion and its practical applications in the treatment of disease.

The author's attitude towards psycho-analysis may be summed up in the following sentence (p. 86): "Patients whose condition requires such a remedy are better left untreated, better in a mental hospital, better dead."

H. T. Thомson.

\section{LETTER TO THE EDITORS}

To THE EDITORS,

The Journal of Laryngology.

SiRs, - I am tempted to contribute to the discussion in your columns on the Blood-Clot Treatment of Simple Mastoidectomy.

Since I had the privilege, three years ago, of observing Mr Tilley's methods at University College Hospital, I have followed them consistently in my own hospital and private practice.

As a rule, healing has been complete within a week, painful dressings are eliminated, and the saving in hospital expenditure is considerable.

As Dr Dan M'Kenzie points out in his letter, there still remains the septic middle-ear, but the risk of reinfection from this source may be minimised by free incision of the tympanic membrane and thorough cleansing at the time of operation.

Dr Macnab expresses the opinion generally held when he states that he has been dissatisfied with the original blood-clot method, and it would appear that the new method owes its success to B.I.P.P. rather than to blood-clot.

Dr MacGibbon of Christchurch, N.Z., who opened this discussion, is therefore perfectly just in his condemnatory criticism of the bloodclot method per se.

It is certain, however, that anyone who follows the technique described by $\mathrm{Mr}$ Tilley will be agreeably surprised by the excellent results.-I am, yours, etc.,

Douglas Guthrie.

EDINBURGH. 